\title{
ISSN 2238-118X
}

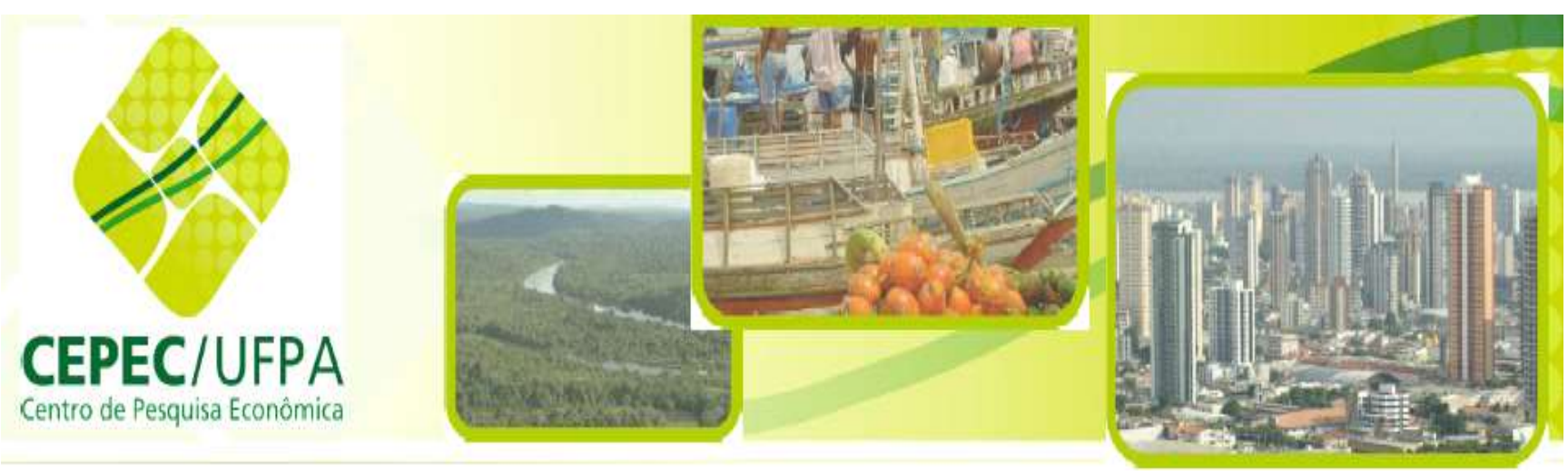

\section{CADERNOS CEPEC}

V. 5 N.04 Abril de 2016

A PRÉ-HISTÓRIA DA MACROECONOMIA: KEYNES E A ECONOMIA CLÁSSICA

Waldemar Sobral Sampaio

Centro de Pesquisas Econômicas da Amazônia

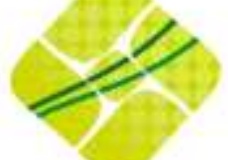

CEPEC/UFPA 


\section{CADERNOS CEPEC}

Publicação do Programa de Pós-graduação em Economia da Universidade Federal do Pará.

Periodicidade Mensal - Volume 5 - N04 - Abril de 2016

Reitor: Carlos Edilson de Oliveira Maneschy

Vice Reitor: Horácio Shneider

Pró-Reitor de Pesquisa e Pós Graduação: Emmanuel Zagury Tourinho

Instituto de Ciências Sociais Aplicadas

Diretor: Carlos Alberto Batista Maciel

Vice Diretor: Manoel Raimundo Santana Farias

Coordenador do Mestrado em Economia: Ricardo Bruno Nascimento

\section{Editores}

José Raimundo Barreto Trindade - Principal

Sérgio Luis Rivero

Conselho Editorial Provisório

$\begin{array}{lll}\text { Armando Souza } & \text { Francisco Costa } & \text { Gilberto Marques } \\ \text { Marcelo Diniz } & \text { José Trindade } & \text { Sérgio Rivero } \\ \text { Ricardo Bruno } & \text { Danilo Fernandes } & \text { Gisalda Filgueiras } \\ & & \text { Márcia Jucá Diniz }\end{array}$

Comentários e Submissão de artigos devem ser encaminhados ao

Centro de Pesquisas Econômicas da Amazônia, através do e-mail: jrtrindade@uol.com.br

Página na Internet: http://www.ppgeconomia.ufpa.br/ 


\section{Cadernos CEPEC \\ Missão e Política Editorial}

Os Cadernos CEPEC constituem periódico mensal vinculado ao Programa de Pós-graduação em Economia do Instituto de Ciências Sociais Aplicadas (ICSA) da Universidade Federal do Pará (UFPA). Sua missão precípua constitui no estabelecimento de um canal de debate e divulgação de pesquisas originais na grande área das Ciências Sociais Aplicadas, apoiada tanto nos Grupos de Pesquisa estabelecidos no PPGE, quanto em pesquisadores vinculados a organismos nacionais e internacionais. A missão dos Cadernos CEPEC se articula com a solidificação e desenvolvimento do Programa de Pós-graduação em Economia (PPGE), estabelecido no ICSA.

A linha editorial dos Cadernos CEPEC recepciona textos de diferentes matizes teóricas das ciências econômicas e sociais, que busquem tratar, preferencialmente, das inter-relações entre as sociedades e economias amazônicas com a brasileira e mundial, seja se utilizando de instrumentais históricos, sociológicos, estatísticos ou econométricos. A linha editorial privilegia artigos que tratem de Desenvolvimento social, econômico e ambiental, preferencialmente focados no mosaico que constitui as diferentes "Amazônias", aceitando, porém, contribuições que, sob enfoque inovador, problematize e seja propositivo acerca do desenvolvimento brasileiro e, ou mesmo, mundial e suas implicações.

Nosso enfoque central, portanto, refere-se ao tratamento multidisciplinar dos temas referentes ao Desenvolvimento das sociedades Amazônicas, considerando que não há uma restrição dessa temática geral, na medida em que diversos temas conexos se integram. Vale observar que a Amazônia Legal Brasileira ocupa aproximadamente 5,2 milhões de $\mathrm{Km} 2$, o que corresponde a aproximadamente $60 \%$ do território brasileiro. Por outro lado, somente a Amazônia brasileira detém, segundo o último censo, uma população de aproximadamente 23 milhões de brasileiros e constitui frente importante da expansão da acumulação capitalista não somente no Brasil, como em outros seis países da América do Sul (Colômbia, Peru, Bolívia, Guiana, Suriname, Venezuela), o que a torna uma questão central para o debate da integração sul-americana.

\section{Instruções para submissão de trabalhos}

Os artigos em conformidade a linha editorial terão que ser submetidos aos editorialistas, em Word, com no máximo 25 laudas de extensão (incluindo notas de referência, bibliografia e anexos). Margens superior e inferior de 3,5 e direita e esquerda de 2,5. A citação de autores deverá seguir o padrão seguinte: (Autor, data, página), caso haja mais de um artigo do mesmo autor no mesmo ano deve-se usar letras minúsculas ao lado da data para fazer a diferenciação, exemplo: (Rivero, 2011, p. 65 ou Rivero, 2011a, p. 65). Os autores devem fornecer currículo resumido. O artigo deverá vir obrigatoriamente acompanhado de Resumo de até no máximo 25 linhas e o respectivo Abstract, palavras-chaves e Classificação JEL (Journal of Economic Literature). 


\title{
A PRÉ-HISTÓRIA DA MACROECONOMIA: KEYNES E A ECONOMIA CLÁSSICA
}

\author{
Waldemar Sobral Sampaio ${ }^{1}$
}

\section{RESUMO}

Este trabalho tem por escopo caracterizar o ponto de partida sobre o qual Keynes delineia suas análises sobre o ciclo de crédito e demanda efetiva em suas obras $\mathrm{O}$ Tratado sobre a Moeda e a Teoria Geral do Emprego, do Juro e da Moeda respectivamente. Procurar-se-á mostrar que, apesar de serem obras com objetivos distintos, as mesmas têm o mesmo ponto de partida, ou seja, a economia clássica em algum de seus fundamentos.

\begin{abstract}
The scope of this paper is to evidence the starting point which John Maynard Keynes develop his analysis about credit cycle and effective demand in the books A Treatise on Money and General Theory of Employment, Interest and Money, respectively. The scopes of the books are singular, but they have the same starting point: the classical economics and its fundamental.
\end{abstract}

PALAVRAS-CHAVES: Metodologia Econômica, Macroeconomia, História do Pensamento Econômico

\section{CLASSIFICAÇÃO JEL: B22, B41, E12}

\footnotetext{
${ }^{1}$ Professor da Faculdade de Economia, Instituto de Ciências Sociais Aplicadas, da Universidade Federal do Pará.
} 


\section{SUMÁRIO}

1. INTRODUÇÃ

2. O TRATADO SOBRE A MOEDA E A ECONOMIA CLÁSSICA ……........................................................

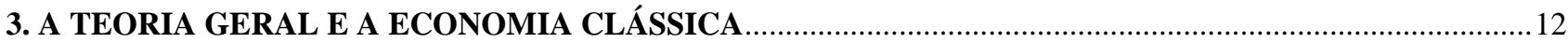

4. LIMITAÇÕES DA ECONOMIA CLÁSSICA: CICLO DE CRÉDITO E DEMANDA EFETIVA ......................16

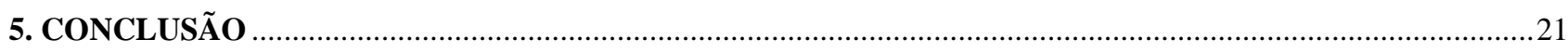

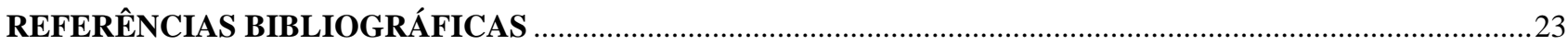




\section{INTRODUÇÃO}

Em seu ensaio sobre o desenvolvimento da macroeconomia, Blanchard (2000) divide a mesma, ao longo do século XX, em três períodos distintos:

- $\quad$ o primeiro, antes de 1940 , é caracterizado como um fase de exploração, onde

alguns elementos importantes foram desenvolvidos, especialmente nos campos da teoria monetária e do ciclo econômico, sem haver, contudo, um programa de pesquisa integrado que direcionasse suas investigações. É de bom tom observar que não havia macroeconomia neste período;

- $\quad$ o segundo, entre 1940 e 1980, foi caracterizado por ter sido um período de consolidação. Uma fase onde um programa de pesquisa foi desenvolvido tendo como núcleo o modelo IS-LM que, por aproximadamente duas décadas, tornou-se a base da macroeconomia tanto para pesquisas teóricas como empíricas;

- o terceiro, a partir de 1980 , foi concebido como um novo período de exploração que enfatizou o papel das imperfeições em macroeconomia a partir da relevância dos salários nominais, preços, informações assimétricas e estruturas dos mercados. Singular a fase anterior, houve muita pesquisa e produção, embora não se tenha chegado a um programa de pesquisa alternativo ao modelo IS-LM.

Este ensaio centra-se na a primeira etapa, especificamente sobre o pensamento de Keynes em duas de suas obras fundamentais: O Tratado sobre a Moeda e a Teoria Geral do Emprego do Juro e da Moeda. Tratam-se de duas obras importantes como objetivos distintos. O primeiro é uma teoria sobre a moeda e a relação desta com o ciclo econômico, enquanto que o segundo trata dos determinantes do produto e do emprego. Contudo, em ambos os trabalhos, o autor em foco parte de um mesmo princípio: a Economia Clássica ${ }^{2}$.

O objetivo deste trabalho é identificar e caracterizar este ponto de partida, bem como delinear suas limitações para o entendimento da realidade econômica que Keynes procurou descortinar em ambas as obras, ou seja, uma situação de equilíbrio caracterizado por um conjunto de fatores que serão desenvolvidos nas demais partes que versam sobre: 
- as equações fundamentais do desenvolvidas no Tratado sobre a Moeda que vão constituir, em um primeiro momento, a versão de Keynes da Teoria Quantitativa da Moeda (TQM);

- o comportamento do mercado e trabalho e a determinação da taxa de juros na economia clássica aludidos na Teoria Geral como o ponto de partida para uma teoria sobre a demanda efetiva;

- as limitações da economia clássica e seus postulados para o entendimento de uma teoria do ciclo de crédito e demanda efetiva tanto no Tratado sobre a Moeda como na Teoria Geral respectivamente;

- a última parte trata da conclusão e procura resgatar os elementos fundamentais deixados por Keynes, em ambas as obras, para o entendimento da macroeconomia.

${ }^{2}$ Keynes (1936) define a economia clássica como aquele conjunto de pensamentos delineados em Ricardo, John S. Mill, Marshall, Edgeworth e Pigou. 


\section{O TRATADO SOBRE A MOEDA E A ECONOMIA CLÁSSICA}

Todo argumento de Keynes desenvolvido ao longo do Tratado sobre Moeda (Tratado) e da Teoria Geral têm por escopo refutar aquilo que o mesmo chamou de economia clássica. Esta parte do trabalho tem por objetivo delinear um conceito de economia clássica na primeira obra, onde, como procurar-se-á mostrar, a teoria em foco está restrita a Teoria Quantitativa da Moeda.

O Tratado é um livro brilhante e toda sua argumentação é desenvolvida de uma forma simples e, ao mesmo tempo, forte. Seu problema fundamental é analisar o ciclo de crédito e sua repercussão sobre o produto e o emprego, o qual é delineado por meio de duas equações fundamentais introduzidas no livro terceiro da referida obra.

Elas são derivadas após uma primeira distinção entre bens de consumo e bens de investimento. Todas as variáveis básicas referem-se à quantidades agregadas que são as que seguem:

- $\mathrm{E}$ = Renda monetária corrente ou os ganhos dos fatores de produção, exceto os lucros anormais;

- $\mathrm{O}=\mathrm{O}$ produto em um período de base;

- I' = Parte de E do setor de bens de investimento, ou seja, o custo monetário corrente de produzir uma unidade bem de investimento;

- $\mathrm{C}=\mathrm{A}$ produção de bens de investimento em um período de base;

- $\mathrm{I}=\mathrm{O}$ valor de mercado de um bem de investimento produzido;

- E - I' = Parte de E dos setor de bens de consumo, ou seja, o custo monetário corrente de produzir uma unidade de bem de consumo;

- $\mathrm{R}=\mathrm{A}$ produção de bens de consumo em um período de base.

Em seguida, Keynes define as variáveis de preços como segue:

- $\mathrm{P}=$ preço corrente dos bens de consumo;

- $\mathrm{P}^{\prime}=$ preço corrente dos bens de investimento;

- $\Pi$ = preço corrente para o produto como um todo = média ponderada entre P e P'.

Keynes implicitamente assume que o período que ele chama de base é o de equilíbrio, ou seja, uma situação onde o preço de demanda é igual ao preço do custo primário tanto para o setor de bens de consumo como para o setor de bens de investimento. Keynes ainda efetivamente define 
(1) o índice de uma taxa monetária de salários W que representa o preço de uma unidade dos fatores de produção de uma maneira geral, e (2) o índice de produto por trabalhador, ou o coeficiente de eficiência, assumindo ainda que o referido índice não varia do setor de bens de consumo para o setor de bens de investimento. A partir dessas definições, uma alteração nos custos de produção com respeito a um período base tanto nos bens de consumo como nos bens de investimento é dada por:

$$
\frac{E}{O}=\frac{W}{e}=W 1
$$

Onde W1 é o que Keynes chamou de taxa de ganho de eficiência, um índice de custo de produção por unidade de produto. A partir dessa relação Keynes derivou suas duas equações fundamentais da forma que segue.

$$
\begin{aligned}
& \text { (i)..P }=\frac{E}{O}+\frac{Q 1}{R}=\frac{W}{e}+\frac{Q 1}{R}=W 1+\frac{Q 1}{R} \\
& \text { (ii).. }=\frac{E}{O}+\frac{Q}{O}=\frac{W}{e}+\frac{Q}{O}=W 1+\frac{Q}{O}
\end{aligned}
$$

Onde Q1 e Q representam os lucros no setor de bens de consumo e para a economia como um todo respectivamente. Dessa forma, a primeira das equações fundamentais representa uma mudança no preços dos bens de consumo poderá advir de uma alteração no custo de produção, bem como de uma unidade de lucros que, no período base, são iguais a zero. Esse raciocínio é o mesmo para a segunda equação com a diferença que agora esta representa o comportamento dos preços da economia como um todo.

O principal significado que Keynes atribui a essas equações demostram que Q1 e Q estão ligados a poupança e ao investimento. Defini-se poupança como a diferença entre E e o consumo, ou seja:

$$
S=E-P R,
$$

onde todas as variáveis estão definidas em termos monetários. Dessa forma, os lucros terão os seguintes formatos:

$$
\begin{aligned}
& Q 1=P R-\left(E-I^{\prime}\right)=I^{\prime}-S \\
& Q=(P R+I)-E=I-S
\end{aligned}
$$


Com isso, dada a definição de lucros, as equações fundamentais podem ser escritas da seguinte forma:

$$
\begin{aligned}
& \left(\text { i)'..P }=\frac{E}{O}+\frac{I^{\prime}-S}{R}\right. \\
& \left(\text { ii)'..П }=\frac{E}{O}+\frac{I-S}{O}\right.
\end{aligned}
$$

Estas equações constituem a forma primária do Tratado. Neste sentido qualquer mudança no nível de preços está diretamente relacionada ao excesso de investimento sobre a poupança.

No contexto de um conceito de economia clássica, Keynes procura explorar o mundo da TQM em uma economia em equilíbrio onde os preços tanto dos bens de consumo como nos bens de investimento são determinados pelo custo dos fatores de produção, ou seja, por fatores reais.

Neste equilíbrio, para uma determinada quantidade de moeda, preço dos fatores de produção e um determinado grau de monopólio, haverá uma taxa de remuneração do empresário que motiva o mesmo a barganhar com os fatores de produção, ou, como Keynes define na obra em foco, a taxa de remuneração normal dos empresários.

Para um produto composto por bens de consumo e bens de investimento e uma renda dos fatores de produção que é utilizada em consumo e poupança, a economia estará em equilíbrio quando a poupança for igual ao investimento que, em conjunto, determinarão a taxa de juros de equilíbrio da economia que torna seus preços iguais ao seu custo de produção. Qual a semelhança desse conceito de equilíbrio com a Teoria Quantitativa de Moeda sintetizada a famosa equação de Fisher?

Considerando a renda monetária dos fatores de produção no nível da circulação industrial, E, pode-se dizer que esta é igual a soma dos depósitos renda vezes sua velocidade de circulação, ou seja:

$$
E=M 1 V 1
$$

Pelas equações (i) e (ii) em um contexto de equilíbrio: 


$$
\begin{aligned}
& \text { (i) } a . . P=\frac{M 1 V 1}{O} \\
& \text { (ii)b..П }=\frac{M 1 V 1}{O} \\
& \text { Logo: } \\
& \Pi=P=M 1 V 1
\end{aligned}
$$

Dessa forma, Keynes chega a uma equação semelhante à de Fisher, exceto pelo fato de que o mesmo leva em consideração o volume de transações, $\mathrm{T}$, e não o volume de produto referente a um ano base O. Esta equação é derivada de (i) a e é representada por:

$$
P O=M 1 V 1
$$

Dessa forma, Keynes, no Tratado, faz alusão à economia clássica pela TQM que constituir o ponto de partida para uma formulação mais ampla que será sua teoria sobre o ciclo de créditos. 


\section{A TEORIA GERAL E A ECONOMIA CLÁSSICA}

Do Tratado até a Teoria Geral passaram-se cinco anos. Na primeira obra, Keynes ainda está bastante ligado no que ele chamou de economia clássica, embora, ao que tudo indique, ele mesmo não estava convencido de que se tratava de uma doutrina propriamente dito, mas de um conjunto de princípios e postulados que, quando integrados, formavam o ponto de partida sobre o qual ele desenvolveu sua argumentação em ambas as obras.

No Tratado, Keynes reconhece que ainda caminha ao longo dos postulados da teoria tradicional, fundamentalmente, na separação entre a teoria da moeda e uma teoria geral de determinação da oferta e da demanda. Contudo, o autor em foco reconhece que houve um progresso considerável à medida a teoria monetária esteve mais próxima da determinação do produto e do emprego, mesmo tendo como ponto de partida a TQM.

As equações fundamentais sintetizam, como já foi dito anteriormente, de uma forma simples e forte, a visão que Keynes tinha do que ele mesmo chamou de economia tradicional, ou seja, para um dado nível de produto, como uma variação na quantidade de moeda afeta o nível de preços.

Ao contrário do Tratado, a Teoria Geral é um livro essencialmente de teoria econômica, ou seja, não existem partes e nem capítulos sobre história ou evidências empíricas sobre um determinado postulado que o autor tivesse por escopo defender. Seu objetivo primário foi colocar em discussão determinados postulados que até então não faziam parte da literatura dos economistas tradicionais, bem como sugerir algumas práticas de política econômica, ou seja, a aplicação daquele marco teórico que ora estava sendo apresentado aos problemas que a realidade exibia.

Superando o pressuposto do produto dado, a Teoria Geral avança para uma teoria de determinação do produto e do emprego, em especial como determinadas formas interagem na determinação das variáveis em tela. Contudo, a exemplo do Tratado, Keynes tem na teoria tradicional seu ponto de partida, considerando que se tratava de um conjunto de conceitos em que a maioria dos economistas estava familiarizada, embora, diante da realidade de sua época, tratava-se 
apenas de um caso especial apenas, ou seja, a realidade era mais complexa e dinâmica do que aqueles postulados em que Keynes havia sido formado descrevia.

Keynes tinha em mente uma economia monetária, aquela onde a moeda é um instrumento de determinação das decisões de gasto dos agentes econômicos, as quais repercutem no comportamento do produto e do emprego. Dessa forma, o ponto de partida para a formulação de uma teoria alternativa do produto e do emprego é o comportamento do mercado de trabalho e de moeda na economia clássica sempre em um contexto de equilíbrio.

Sobre o nível de emprego, este é determinado em um mercado específico a partir da interação entre as curvas de oferta e demanda por trabalho que, em conjunto, em um contexto de agentes otimizadores, vão determinar o produto marginal do trabalho e sua desutilidade marginal respectivamente em um modelo que tem por escopo a determinação do salário real.

Assim, movimento nas curvas de oferta e demanda por trabalho determinam pontos de equilíbrio de salário real e emprego alternativos na medida em que tais movimentos afetam a primeira variável que é a base sobre a qual trabalhadores e firmas vão tomar suas decisões quanto a ofertar ou demandar uma determinada quantidade de trabalho. No mundo da teoria que Keynes chamou de tradicional, tanto os trabalhadores como as firmas determinam o nível de emprego e, por conseqüência, o nível de produto.

Esta abordagem sobre a determinação do nível de emprego e, por conseqüência, do nível de atividade econômica está relacionada a um contexto onde não existe desemprego, exceto quando este for voluntário ou friccional, o qual é determinado pelo grau de organização e previsão do mercado, ou seja, a economia clássica descreve um mundo de pleno emprego, ou seja, todos aqueles que estão dispostos a ofertar trabalho ao salário real vigente conseguem alocação no mercado.

Esta é a essência da teoria do emprego que Keynes aborda ao longo de sua Teoria Geral, para o qual é apenas, a exemplo de qualquer postulado da economia clássica, um caso especial. Este foi seu entendimento sobre a obra The Theory of Unemployment de A. C. Pigou. Aparentemente, nas palavras de Keynes, trata-se uma teoria simples e óbvia sobre os determinantes do nível de emprego que ignorava aspectos bastante significativos da realidade econômica que 
Keynes vivia como o grau de organização na vida econômica, em especial os sindicatos, bem como a presença do desemprego involuntário.

O próximo passo é o comportamento do mercado monetário. A exemplo do comportamento do mercado de trabalho, o estudo deste é relativamente simples, embora Keynes considere difícil fazer uma exposição precisa a partir dos tratados de economia clássica por ele investigados. Nesta linha de raciocínio, Keynes faz alusão aos trabalhos de Ricardo e Marshall sobre a determinação da taxa de juros.

Sobre a obra de Ricardo, Keynes a considera válida em um contexto de longo prazo onde sempre prevalece o pleno emprego. Neste sentido, considerando que as curvas de oferta e demanda por trabalho são estáveis, existe apenas uma taxa de juros compatível com o longo prazo.

Contudo, Keynes argumenta que os ricardianos não deram a devida importância do sistema bancário e a capacidade deste em determinar uma taxa de juros que não é necessariamente é a de pleno emprego, mesmo em se tratando de um contexto de longo prazo. Nesta mesma linha de raciocínio, ainda seguindo Keynes, Ricardo e seus seguidores teriam ignorando a presença da autoridade monetária e a capacidade desta em determinar uma taxa de juros compatível com diversos pontos de equilíbrio de longo prazo.

Ainda na Teoria Geral, Keynes faz referência a Marshall, para o qual "o juro, sendo o preço pago pelo uso de capital em qualquer mercado, tende para o equilíbrio, no qual a procura agregada de capital no dito mercado, e essa taxa de juros, é igual ao estoque agregado, que nele se apresenta a mesma taxa." (Keynes, 1936 pp. 150)

A passagem de Marshall citada por Keynes, talvez justifique a dificuldade que o último teve em abordar com a devida precisão a teoria clássica da taxa de juros. Keynes alerta que Marshall utiliza os termos 'capital' e não moeda e substitui por 'estoque' a palavra empréstimo, onde o primeiro é a demanda e o segundo á a oferta, logo a taxa de juros constitui-se em uma variável que torna ambas as magnitudes iguais e a dificuldade reside no fato de que o juro, embora seja um conceito estritamente monetário é colocado em uma economia que não tem moeda.

Por fim, a dinâmica desse mercado é, basicamente, a mesma do mercado de trabalho, mesmo considerando as imperfeições observadas, o objetivo é a determinação da taxa de juros real e sua flutuação em um contexto onde pontos de equilíbrio alternativos são estudados, os quais 
derivam de uma alteração entre a curva de demanda por investimento (ou por fundos emprestáveis) e oferta de poupança (ou de fundos emprestáveis) sempre, não é demais repetir, em um cenário de longo prazo onde o produto é determinado pelo nível de emprego e este no mercado de trabalho.

Esta parte do trabalho não estaria completa sem uma abordagem sobre a Lei dos Mercados de Say, ou, como é vulgarmente conhecida, A Lei de Say onde 'toda a oferta cria sua própria procura'. A exemplo dos demais postulados descritos acima, a Lei de Say é uma caso especial de uma economia que tem na oferta seu ponto de partida para descrever a dinâmica da economia. Trata-se de e uma economia de trocas e não de uma economia monetária, ou seja, a moeda não é um instrumento de decisão dos agentes econômicos.

Este constitui o âmago daquilo que Keynes chamou de teoria clássica onde o mesmo passa a impressão de ter sido ainda muito forte e presente na opinião da comunidade de economistas para os quais ele dirigiu a Teoria Geral. Seu objetivo foi chamar a atenção para suas imperfeições e, o mais importante, a incompatibilidade da teoria em foco com a realidade vivida pelo mesmo.

Pode-se, neste momento, rematar que Keynes, tanto no Tratado quanto na Teoria Geral, procurou, a partir de uma visão de mundo econômico compatível com mentalidade dos economistas de sua época para, conduzir tal comunidade para uma visão de mundo que apenas havia predominado, conforme suas próprias palavras, no submundo da heterodoxia ou entre os economistas ditos de esquerda. Esta economia que Keynes chamou de tradicional tinha por fundamento, conforme colocado até agora, as seguintes hipóteses:

1. a Lei de Mercados de Say;

2. os mercados auto-ajustáveis; e

3. a Teoria Quantitativa da Moeda. 


\section{LIMITAÇÕES DA ECONOMIA CLÁSSICA: CICLO DE CRÉdITO E DEMANDA EFETIVA}

As partes pretéritas deste trabalho tiveram por escopo delinear as hipóteses que são o ponto de partida que Keynes utilizou para desenvolver suas teorias sobre o ciclo de crédito e sobre a demanda efetiva no Tratado e na Teoria Geral respectivamente. Como o título acima sugere, pode-se questionar que está o além de todos os fundamentos até o momento expostos? Foi o que Keynes tentou mostrar a partir dos postulados já citados que o mesmo chamou de economia clássica.

Pode-se iniciar por uma posição de equilíbrio onde, por definição, a taxa de juros de mercado é igual a taxa natural tal que o investimento seja igual a poupança. Considerando que esse estado é rompido por um aumento na quantidade de moeda, uma parte desta será absorvida pela circulação industrial, repercutindo em P' gerando, lucros que os empresários não estavam esperando, os 'windfall profits's.

Neste ponto é de bom tom fazer uma pausa para notar que um aumento de P' com relação à P não tem um papel sistemático neste processo dinâmico. A análise de Keynes no Tratado considera que uma variação em P' e P ocorrem na mesma proporção, ou seja, não existe variação no preços relativos dos bens de investimento sobre os bens de consumo.

A análise de Keynes parte do princípio que um aumento na quantidade de moeda eleva as reservas bancárias, induzindo a uma redução na taxa de juros para aqueles que vão fazer empréstimos. Como resultado, os tomadores serão motivados a aumentar suas demandas pelos mesmos para fazer frente a novos projetos o que resulta em um desequilíbrio entre o investimento e a poupança, gerando excesso de lucros.

Como resultado dos lucros, uma expansão do produto das firmas aumenta a demanda por fatores, provocando um aumento da taxa de salários por unidade de custo de produção. Esse processo continua até que esse aumento seja suficiente para eliminar o aumento de lucros gerado na esfera da circulação industrial.

\footnotetext{
${ }^{3}$ Defini-se windfall profits como sendo aquele lucro que os empresários não esperam, muito diferente da remuneração normal dos empresários que Keynes define como aquela onde os empresários estão dispostos a barganhar com os fatores de produção.
} 
Com isso, Keynes explica o ciclo de crédito como sendo oscilações no excesso de investimento sobre a poupança que levam a alterações no poder de compra da moeda, os quais derivam de fatores puramente monetários.

Dessa forma, Keynes enfatiza que para efeito de comparar duas posições de equilíbrio a TQM tradicional permanece válida. O propósito da obra em tela foi estender a referida teoria para uma economia que tem o sistema bancário desenvolvido e analisar a dinâmica do movimento entre dois pontos de equilíbrio. O papel da taxa de juros neste cenário é o de igualar poupança e investimento nas equações fundamentais.

Assim, o Tratado tem por ponto de partida a TQM, em especial uma taxa de juros de equilíbrio entre poupança e investimento. Ainda em sua análise do papel da taxa de juros natural e de mercado, Keynes faz alusão a Wicksell, contudo, para o primeiro, a taxa natural e aquela que iguala a poupança e o investimento em um certo valor de mercado.

$\mathrm{O}$ autor ainda atribuiu a suas equações fundamentais sua principal contribuição para a teoria monetária de sua época bem como a considerou como uma obra que seria a última palavra em economia monetária pura como aplicada.

A Teoria Geral tem sua tônica sobre a demanda efetiva e também parte, como já foi colocado, de pressupostos puramente clássicos em sua análise. Contudo, diferentemente de seu Tratado, as hipóteses colocadas sobre a economia clássica anteriormente são completamente dispensáveis do ponto de vista de uma teoria alternativa, ou seja, na construção de uma nova base conceitual mais realista segundo seu autor. Pode-se dizer que, diferentemente do Tratado, Teoria Geral é uma obra de ruptura com a visão de mundo que Keynes chamou de tradicional.

Sobre o mercado de trabalho, Keynes mantém o primeiro pressuposto clássico sobre a questão da demanda por trabalho e abandona por completo o segundo sobre a oferta. O nível de emprego agora é determinado somente pelo lado das firmas a partir do conceito de oferta de demanda agregadas e que agora têm um caráter puramente expectacional.

Assim, tanto a oferta como a demanda agregadas são definidas em termos de um produto expectacional que leva os empresários a alocar um determinado volume de trabalho sobre o qual os mesmos têm uma expectativa de receita. A manutenção do primeiro pressuposto talvez 
derive de que este produto que leva os empreendedores a alocar um determinado contingente de mão-de-obra é aquele que maximize sua receita.

Com isso, Keynes define demanda efetiva com aquele nível de atividades que será o resultado da formação de expectativas, seja quanto a produção ou investimento, sendo que, no primeiro caso, os empresários vislumbram um horizonte de curto prazo e, no segundo, de longo prazo.

Neste sentido, a ruptura de Keynes com a economia tradicional, pelo lado do mercado de fatores, torna-se desnecessário um curva de oferta de trabalho, dado que toda a decisão de alocação do referido custo de produção está na mão agora de quem demanda trabalho. Por esta razão, é possível que um determinado volume de trabalhadores, dispostos a aceitar o salário nominal vigente esteja sem alocação produtiva em função do estado de expectativas dos empresários.

Esta é a razão pela qual Keynes sente a necessidade de introduzir o conceito de desemprego involuntário, ou seja, para um dado nível de demanda efetiva que corresponde a um produto expectacional, haverá trabalhadores involuntariamente desempregados quando a oferta de trabalho for maior que o referido nível de emprego existente.

Pelo lado do consumidor que, na teoria clássica, na definição Keynes, tinha a propriedade de determinar o nível de demanda por um determinado bem, no mundo novo para o qual Keynes teve a pretensão de conduzir os economistas de sua época foi colocado em uma posição marginal, ou, praticamente, inexistente. A categoria consumo que tinha a conotação de satisfação de necessidades a partir de uma restrição orçamentária é agora tido como um tipo de gasto medido em termos agregado, ou seja, no nível de consumo da sociedade como um todo. A relação da renda com o gasto em consumo é dada pela famosa propensão a consumir, ou seja, a parcela da renda que os agentes pretendem gastar em consumo.

Toda a problemática da demanda efetiva é o resultado de que o gasto em consumo será sempre menor que o total da renda, havendo, com isso, a necessidade de formular uma teoria do investimento. Assim, por mais que haja uma variação na renda, pela Lei Psicológica Fundamental, haverá sempre uma variação no consumo, porém em uma proporção menor, o que leva Keynes a concentrar suas atenções sobre o investimento, passando por uma teoria da taxa de juros e chegando a um elemento fundamental em sua formulação: a preferência pela liquidez. 
Na visão de mundo dos economistas de suas épocas, a moeda não faz a parte da decisão dos agentes, ou seja, ela é apenas um meio de troca em um contexto de um mundo que e desprovido de um sistema bancário desenvolvido ou mesmo que não tem moeda. Quando muito, a relação da moeda com o agente econômico faz parte de uma otimização intertemporal que o leva a consumir no presente ou no futuro tendo a taxa de juros como o elemento determinante da decisão do mesmo.

A visão proposta por Keynes é de ruptura por completo com esta visão de mundo que o mesmo tem em mente propõe visão de uma economia monetária. Dessa forma, a moeda agora é um ativo, ou seja, em conjunto com os demais, é uma forma de um agente econômico transportar riqueza ao longo do tempo, embora a moeda em si não tenha rentabilidade, mas, pela propriedade da liquidez ela pode dar para aquele que a porte um prêmio, exatamente por tê-la.

O que determina a propensão do agente econômico para reter uma determinada quantidade de moeda ? Dentre os motivos abordados na Teoria Geral, um ganha destaque em sua análise: a procura especulativa por moeda.

Considerando que a moeda tem as propriedades supracitadas, novamente entra o elemento expectativa que vai definir em que grau um determinado agente está disposto a conservar recursos na forma liquida. Dentre os elementos que vão influenciar em tal decisão estão o comportamento da taxa de juros, bem como o da política monetária, ou seja, como esses elementos vão se comportar para que um determinado agente abra mão, em um determinado grau, de seu prêmio de liquidez.

Como acontece em boa parte da análise keynesiana, não existe uma conclusão definitiva e toda e qualquer tentativa de fazê-lo, em que pese seu grau de validade, será sempre relativa perto de outras possibilidades que um determinado contexto econômico oferece. Pode-se apenas dizer que para uma determinada oferta de moeda, conjugada com um grau de preferência pela liquidez, terá como resultado uma taxa de juros de mercado.

Esta última, a seu turno, em conjunto com a eficiência marginal do capital, vai determinar o gasto em investimento, perfazendo a lacuna que havia sido deixada entre o nível de produto e o gasto em consumo. Em que grau os referidos gastos vão cobrir o hiato entre o produto e 
o gasto em consumo ? Isso novamente em Keynes é muito relativo e vai depender da precisão em que os agentes formaram suas expectativas.

Este último elemento torna a Teoria Geral um livro que conjuga beleza e complexidade. O primeiro elemento justifica-se pela maneira como seu autor constrói seus conceitos e formula seu argumentos de maneira lógica e coerente com sua proposta. O segundo deriva da relatividade de seu pensamento em um contexto onde nada é conclusivo, ou seja, por mais correta que seja a combinação dos elementos fundamentais do livro, jamais haverá uma conclusão definitiva sobre como poderá ser o comportamento de uma realidade econômica. 


\section{CONCLUSÃO}

O que justifica o título deste trabalho? Propositadamente, foram deixadas todas as justificativas pertinentes para esta etapa, dado que alguns esclarecimentos fazem-se necessários. Existe uma concordância com a divisão da história da macroeconomia feita por Blanchard (2000), adicionando que a primeira etapa constitui a pré-história da macroeconomia.

Justifica-se a utilização do termo em função da ausência de um programa de pesquisa integrado que direcionasse as pesquisas teóricas e empíricas no campo da macroeconomia. Esse motivo talvez justificasse a utilização da expressão acima. Adicionalmente, ainda seguindo Blanchard (2000), toda a discussão da época foi centralizada em torno das teorias monetária e o ciclo econômico. $\mathrm{O}$ argumento do autor em foco pode ser perfeito com o fato de que esta época foi de conjecturas e refutações sobre, como coloca Keynes, um conjunto de postulados que o mesmo, valendo-se de uma expressão de Marx, chamou de economia clássica.

Keynes, em suas duas obras colocadas ao longo deste trabalho, tem este tipo de procedimento, ou seja, parte de um mesmo ponto em ambas as obras. No Tratado, o autor tenta colocar a teoria quantitativa da moeda em um contexto de uma economia com um sistema bancário desenvolvido e o faz por meio de suas duas equações fundamentais.

Contudo, como uma economia comporta-se na trajetória entre dois pontos de equilíbrio alternativos? A resposta para essa questão é uma teoria do ciclo de créditos observada na parte pretérita que teve por mérito aproximar a teoria monetária da determinação do produto e do emprego, mesmo que em um contexto onde o produto é dado em um cenário onde prevalece a TQM.

Em uma economia em desequilíbrio, uma variação na quantidade de moeda tem repercussão sobre o nível de atividade econômica até que os efeitos dessa variação sejam absorvidos por algum aumento de preços. Indubitavelmente, não deixou de representar um avanço na medida em que deslocou a análise econômica para uma posição fora do equilíbrio.

Na Teoria Geral, Keynes tem a pretensão de identificar os elementos em que seus leitores analisavam a realidade econômica de suas épocas para, em seguida, tentar introduzir uma taxionomia alternativa, embora, diferentemente da primeira obra, Keynes não viu utilidade naquele conjunto de postulados dos quais ora partia. 
Alternativamente a uma economia comandada pela oferta, Keynes introduziu conceitos novos para a realidade dos economistas de sua época como propensão a consumir, eficiência marginal do capital e preferência pela liquidez que, em um contexto de expectativas, vão determinar em conjunto o nível de produto e emprego. Indubitavelmente, foram contribuições significativas, porém seu entendimento ficou a posteridade.

Uma teoria da demanda efetiva como proposta na obra supracitada exigiu um esforço de entendimento que, até aquele momento, só se via no mundo dos economistas heterodoxos que refutavam a economia clássica e seus postulados por definição. Por esta razão, não é aleatório o argumento de que a principal obra de Keynes não teve o entendimento por parte dos leitores para os quais se dirigiu. 


\section{REFERÊNCIAS BIBLIOGRÁFICAS}

ACKLEY, Gardner (1978). Teoria Macroeconômica. Trad. David Carneiro Jr. São Paulo, Pioneira. BARRÈRE, Alain (1995) . Keynes aujourd'hui: Théories et Politiques. Paris, ECONOMICA BLANCHARD, O (2000). What We Know About Macroeconomic that Fisher e Wicksell did not? Massachusetts, National Bureau of Economic Research. Working Papers 7550.

CHICK, Victória (1993) . Macroeconomia Após Keynes: um reexame da teoria geral. Trad. Jefferson Chaves e Daniel Camarinha. Rio de Janeiro, forense Universitária.

HANSEN, Alvin H (1987). Guia para Keynes. Trad. Donalson M. Garschagen. São Paulo, Vértice. KEYNES, Jonh M (1982) . A Teoria Geral do Emprego, do Juro e da Moeda. Trad. Mário R. da Cruz. São Paulo, Atlas.

(1992). Breve Tratado sobre la Reforma Monetaria. Trad. Carlos R. Braun. México, Fundo de Cultura Econômica.

Economic Society.

(1988). A Treatise on Money: The Pure Theory of Money. England, Royal (1988). A Treatise on Money: The Applied Theory of Money. England, Royal Economic Society.

SHAPIRO, Edward (1985). Análise Macroeconômica. Trad. Augusto Reis. São Paulo, Atlas. SZMRECSÁNYI, Tomás (1984). Keynes. Col. Grandes Cientistas Sociais. São Paulo, Ática.

Recebido em Fevereiro de 2015.

Aceito para publicação em Setembro de 2015. 